\title{
Accessing care in multidisciplinary pain treatment facilities continues to be a challenge in Canada
}

\author{
Manon Choinière, ${ }^{1,2}$ Philip Peng, ${ }^{3,4}$ Ian Gilron, ${ }^{5,6}$ Norman Buckley, \\ Owen Williamson, ${ }^{9,10}$ Audree Janelle-Montcalm, ${ }^{2}$ Krista Baerg (iD) , 11,12 \\ Aline Boulanger, ${ }^{1,13}$ Tania Di Renna, ${ }^{14,15}$ Gordon Allen Finley, ${ }^{16,17}$ Howard Intrater, $^{18,19}$ \\ Brenda Lau, ${ }^{20,21}$ John Pereira ${ }^{22,23}$
}

For numbered affiliations see end of article.

\section{Correspondence to} Dr Manon Choinière, Department of Anesthesiology and Pain Medicine, Université de Montréal Faculté de Médecine, Montreal, QC H3T 1J4, Canada; manon.choiniere@umontreal.ca

Received 21 July 2020 Revised 26 August 2020 Accepted 31 August 2020 Published Online First 6 October 2020
Check for updates

(C) American Society of Regional Anesthesia \& Pain Medicine 2020. No commercial re-use. See rights and permissions. Published by BMJ.

To cite: Choinière $M$, Peng P, Gilron I, et al. Reg Anesth Pain Med 2020:45:943-948

\section{ABSTRACT}

Background Multidisciplinary pain treatment facilities (MPTFs) are considered the optimal settings for the management of chronic pain (CP). This study aimed (1) to determine the distribution of MPTFs across Canada, (2) to document time to access and types of services, and (3) to compare the results to those obtained in 2005-2006.

Methods This cross-sectional study used the same MPTF definition as in 2005-2006 - that is, a clinic staffed with professionals from a minimum of three different disciplines (including at least one medical specialty) and whose services were integrated within the facility. A comprehensive search strategy was used to identify existing MPTFs across Canada. Administrative leads at each MPTF were invited to complete an online questionnaire regarding their facilities.

Results Questionnaires were completed by 104 MPTFs (response rate $79.4 \%$ ). Few changes were observed in the distribution of MPTFs across Canada compared with 12 years ago. Most (91.3\%) are concentrated in large urban cities. Prince Edward Island and the Territories still lack MPTFs. The number of pediatric-only MPTFs has nearly doubled but remains small $(n=9)$. The median wait time for a first appointment in publicly funded MPTFs is about the same as 12 years ago ( 5.5 vs 6 months). Small but positive changes were also observed.

Conclusion Accessibility to public MPTFs continues to be limited in Canada, resulting in lengthy wait times for a first appointment. Community-based MPTFs and virtual care initiatives to distribute pain services into regional and remote communities are needed to provide patients with $\mathrm{CP}$ with optimal care.

\section{INTRODUCTION}

About one in five Canadians reports from chronic pain (CP). ${ }^{12}$ Persistent pain has numerous deleterious effects on physical, psychological, and social functioning and thereby contributes deteriorating health-related quality of life. ${ }^{3-6}$ While Canadian data are less robust, the estimated total direct healthcare costs of CP and its indirect costs related to loss of productivity range between 560 and 635 billion annually in the USA. ${ }^{7}$ Applying these estimates to the Canadian population, the total annual costs of CP would exceed 56 billion. ${ }^{8}$

The International Association for the Study of Pain recommends an integrated multimodal care model for the management of CP because it is complex phenomenon which is multidimensional in nature. ${ }^{910}$ In its 2019 report, the Canadian Pain Task Force concluded that pharmacological treatments are most effective when combined with physical, psychological, and self-management techniques within an integrated multidisciplinary pain management plan. $^{8}$

Multidisciplinary pain treatment facilities (MPTFs) exist within tiered pain management networks to provide integrated multimodal care for people living with CP, particularly when it is associated with mood and substance use disorders. MPTFs also provide interventional procedures, education, training, research, and support to those who provide care in community or primary care settings.

In 2005-2006, Peng et al found that the median wait time for a first consultation in a Canadian public MPTF was 6 months and could be as long as 5 years. ${ }^{11}$ Furthermore, $80 \%$ of clinics were concentrated in major urban cities and there were none on Prince Edward Island or in the Territories. Since 2005, the population of Canada has increased $16.9 \%$ and aged, with the proportion of those 65 years and older having augmented from 13.1\% to $17.5 \%,{ }^{12} 13$ resulting in a growing demand on MPTF's services. An update of the Canadian MPTFs landscape is also warranted in the context of the opioid crisis and its impact on our healthcare system.

Furthermore, in recent months, the capacity to maintain pain services has been challenged by the impact of the COVID-19. ${ }^{14}$

In laying the foundation for the development and implementation of a Canadian national pain strategy, it is important to review MPTFs in order to inform the development of policy that improves the care of those living with $\mathrm{CP}$ and plans for continuity of care in times of crisis such as the COVID-19 pandemic. ${ }^{14}$

The aims of this study were (1) to examine the current distribution of MPTFs in Canada's 10 provinces and 3 territories, (2) to document time to access and types of services, and (3) to compare these results to those obtained in 2005-2006.

\section{METHODS}

This study used the same overall methods as the ones we used in 2005-2006. ${ }^{11}$ A comprehensive search strategy coupled to the administration of a self-reported questionnaire were used to map and 
the MPTFs available in Canada and document their characteristics. Data were collected between July 2017 and November 2018.

\section{Definition of MPTFs and eligibility criteria}

The present study used the same definition of MPTFs and eligibility criteria as used by Peng et $a l^{11}$ — that is, "To be included in the study, the clinics had to 1) advertise itself as a pain clinic or a pain center providing specialized multidisciplinary services for diagnosis and management of patients with chronic nonmalignant pain; and 2) be staffed with professionals from a minimum of three different health care disciplines (whose services were available and integrated within the pain clinic or center) including at least one medical specialty." Modalityoriented clinics-that is, a healthcare facility offering a specific type of treatment without comprehensive assessment or management of CP pain (eg, nerve block clinic, acupuncture clinic, and so on) or pain clinics operated by an isolated solo practitioner were excluded.

\section{Search strategy}

A preliminary list of existing MPTFs was prepared using multiple sources of information. MPTFs previously identified in our 2005-2006 study were included in this list. All members of the Canadian Pain Society were sent a letter of information inviting medical directors of MPTFs to participate in our study. In addition, we consulted the list of MPTFs available on the web sites of the Canadian Pain Coalition and the Association québécoise de la douleur chronique. We also contacted members of the Academic Pain Directors of Canada, the Pain Medicine Physicians of British Columbia Society, and the Quebec Pain Research Network. Finally, we conducted an internet search per province and territory to identify additional MPTFs using keywords such as pain clinic, pain center, pain service, and pain facility. Clinics considered as non-eligible based on the information provided on internet were not contacted. To ensure the completeness of our preliminary list, we identified in each province/territory a study "champion"- that is, a clinician who had an excellent knowledge of pain treatment facilities in her/his province through her/ his contacts with professional organizations or provincial pain societies. These study representatives reviewed our list, added missing MPTFs, and helped in follow-up by contacting administrative leads who did not return the questionnaire.

\section{Data collection}

Administrative leads of the identified MPTFs were sent by email an invitation letter, which included the URL link to our study questionnaire. By responding to the questions, the representatives consented that the contact information of their clinics be posted on the Canadian Chronic Pain Network website (https:// cpn.mcmaster.ca). Between 30 and $45 \mathrm{~min}$ were required to complete the questionnaire. The research assistant (RA) sent a reminder email to administrative leads who did not fill out the study questionnaire and invited them to return it as soon as possible. In the event that there was still no response, the RA recontacted the clinic representative by email or phone. If she was not successful in obtaining the requested information after three attempts, she informed the provincial study champion and ask her/him to contact the administrative lead. On receiving the questionnaire, the RA reviewed it and if there were unclear or missing answers, she contacted the respondent by email or telephone to obtain the information. The RA sent to the clinic representative the unique Internet link corresponding to the questionnaire she/he partly completed or a Word version of the questionnaire where the answers to be revised were highlighted.

On the first page of the online questionnaire, the MPTF definition and study selection criteria described above were detailed. If the MPTFs did not meet these criteria, they were not invited to complete the rest of the questionnaire. An adapted and updated version of the questionnaire we used in our 2005-2006 study ${ }^{11}$ was employed and covered the following items: (1) the MPTF's organizational structure; (2) clinical activities such as the volume of patients (new cases, follow-up cases), patients' inclusion/exclusion criteria, length of wait list, type of pain conditions treated, and therapeutic modalities offered; (3) staff composition and availability; (4) teaching and research activities; and (5) type of funding. The questionnaire is included as online supplemental file 1 . Not all the information collected with the questionnaire is described in the present article as other results will be presented in separate manuscripts which are currently in preparation.

\section{Statistical analysis}

Standard descriptive statistics including frequencies, medians, and 25\%-75\% IQR were calculated using SPSS V.25 (Chicago, Illinois, USA).

\section{RESULTS}

Results of our pan-Canadian search strategy revealed 222 potentially eligible clinics and the study questionnaire was sent to all of them. Although multiple attempts were made to contact them, $12.2 \%$ of the clinics $(27 / 222)$ did not reply. Thus, it is unknown if they met the above selection criteria. After screening for eligibility of the other clinics, $41.0 \%(91 / 222)$ of them did not meet the selection criteria. Among eligible clinics, 79.4\% (104/131) completed the questionnaire. A total of 117 clinics out of 222 $(52.7 \%)$ clinics had be recontacted because they did not return the study questionnaire or did not fill it out in its entirety.

\section{Distribution of MPTFs}

Table 1 presents the 2005-2006 and 2017-2018 distributions of the MPTFs in different Canadian provinces. As in 2005-2006, Prince Edward Island and the three Canadian territories still did not have a MPTF while Newfoundland continued to have only one. In 2017-2018, the number of MPTFs in six provinces was slightly higher than in 2005-2006, but there was an important decrease in Ontario and Saskatchewan. As shown in table 1, the majority of the MPTFs (91.3\%) were concentrated in large cities. It was estimated that one MPTF served an average of 354000 Canadians. Almost two-thirds of the MPTFs (64.9\%) are university-affiliated. A large percentage of MPTFs $(73.7 \%)$ accept adult patient referrals exclusively. Compared with 12 years ago, the number of MPTFs specifically dedicated to children and youth has nearly doubled ( $n=5$ vs $n=9$ ). The major source of funding for patient services $(>50 \%$ ) came from the public sector (provincial insurance plan) in 97 of the 104 MPTFs (93.3\%) and from the private sector (compensation agencies, insurance companies, patient contribution (out-of-pocket) or philanthropic donations) in seven of them (6.7\%). This contrasts with previous results from Peng et al in 2007, ${ }^{11}$ where the percentage of privately-funded MPTFs was much higher (40\%).

Considering the very small number of private MPTFs identified in the present study, they were excluded from the rest of the analyses. The same was true for four MPTFs for which less than $10 \%$ of the questionnaire had been completed, leaving a sample size of 93 clinics. 
Original research

\begin{tabular}{|c|c|c|c|c|}
\hline Province & $\begin{array}{l}2005-2006 \\
\text { N }\end{array}$ & $\begin{array}{l}2017-2018 \\
\text { N }\end{array}$ & $\begin{array}{l}\text { 2017-2018 } \\
\text { Per population }\end{array}$ & $\begin{array}{l}2017-2018 \\
\text { Urban area }(n, \%)\end{array}$ \\
\hline Newfoundland & 1 & 1 & $1 / 527 \mathrm{~K}$ & $1(100)$ \\
\hline Prince Edward Island & 0 & 0 & $0 / 152 \mathrm{~K}$ & $\mathrm{~N} / \mathrm{A}$ \\
\hline Nova Scotia & 4 & 7 & $1 / 136 \mathrm{~K}$ & $3(43)$ \\
\hline New Brunswick & 3 & 5 & $1 / 154 \mathrm{~K}$ & $4(80)$ \\
\hline Quebec & 26 & 28 & $1 / 298 \mathrm{~K}$ & $27(96)$ \\
\hline Ontario & 35 & 25 & $1 / 568 \mathrm{~K}$ & $24(96)$ \\
\hline Manitoba & 1 & 4 & $1 / 336 K$ & $4(100)$ \\
\hline Saskatchewan & 13 & 3 & $1 / 385 \mathrm{~K}$ & $3(100)$ \\
\hline Alberta & 12 & 18 & $1 / 238 \mathrm{~K}$ & $16(89)$ \\
\hline British Columbia & 7 & 13 & $1 / 381 \mathrm{~K}$ & $13(100)$ \\
\hline Three Territories & 0 & 0 & $0 / 123 K$ & N/A \\
\hline Canada & 102 & 104 & $1 / 354 K$ & $95(91)$ \\
\hline
\end{tabular}

MPTFs, multidisciplinary pain treatment facilities; N/A, not applicable.

\section{Workload and wait times in public MPTFs}

More than $80 \%$ of public MPTFs (82.6\%) reported operating at least 48 weeks per year (median=50, IQR: 48-52). Approximately, this represented a total of 57698 new consultations and 374182 follow-up visits in the past year across the country. In 2005-2006, these numbers were 46000 and 529 000, respectively, suggesting that the MPTFs have been successful in increasing their number of new consultations over time.

Figure 1 shows that the median wait times for a first appointment at public MPTFs were highly variable from one province to another. The lowest wait time was located in Ontario (1.5 months), while the longest was in New Brunswick (23.3 months). The median wait time across the country was 5.5 months $(2.0-9.0)$, a result which is almost identical to the one found in 2005-2006 (median: 6months $(2-14)){ }^{11}$ The wait time exceeded 1 year in one out of five clinics $(22.3 \%)$ and could be as long as 4.3 years, suggesting some slight improvement compared with 2005-2006 where these numbers were $31 \%$ and 5.0 years.

\section{Clinical activities of public MPTFs}

As found in 2005-2006, low back pain ranked as the most commonly managed pain syndrome (70.8\%). It was followed by fibromyalgia $(9.0 \%)$, neuropathic pain $(4.5 \%)$, and headache/migraine (3.4\%). Pharmacological therapies are offered in almost all MPTFs (89.2\%).

Opioids are prescribed in most MPTFs (80.6\%); 62.7\% of them sign an opioid contract agreement with the majority of their patients and nearly $2 / 3(61.8 \%)$ use urine-screening tests. More than half of the MPTFs (55.9\%) offer assistance to obtain medical marijuana while $45.1 \%$ reported prescribing medical marijuana.

Canadian public MPTFs also offer a wide variety of nonpharmacological treatments including interventional, physical, and psychological modalities (figures 2-4). Similarly to that reported in 2005-2006, three quarters of the MPTFs provide at least one type of interventional technique (2005-2006: 75\%; 2017-2018: 78\%). An increase in the offer of physical therapy

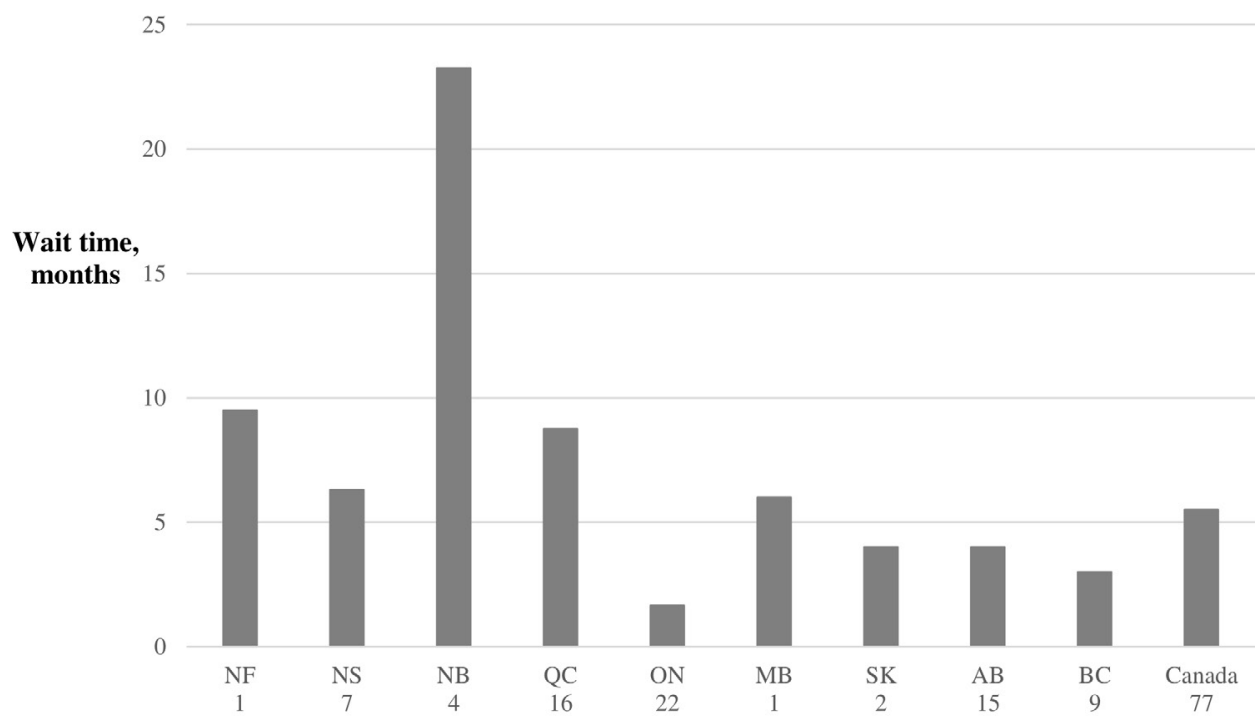

Provinces

Figure 1 Median wait time to patients' first appointment in publicly funded MPTFs in different provinces in Canada and overall. Wait time data were not available for 18 of the participating MPTFs even though they were contacted on several occasions. They did not answer either because they did not want to provide this information, they did not know the exact number, or they felt that their estimation would not be accurate enough. The number of MPTCs per province is indicated along the $\mathrm{X}$ axis under each province. AB, Alberta; BC, British Columbia; MB, Manitoba; MPTFs, multidisciplinary pain treatment facilities; NB, New Brunswick; NF, Newfoundland; ON, Ontario; QC, Quebec; SK, Saskatchewan. 


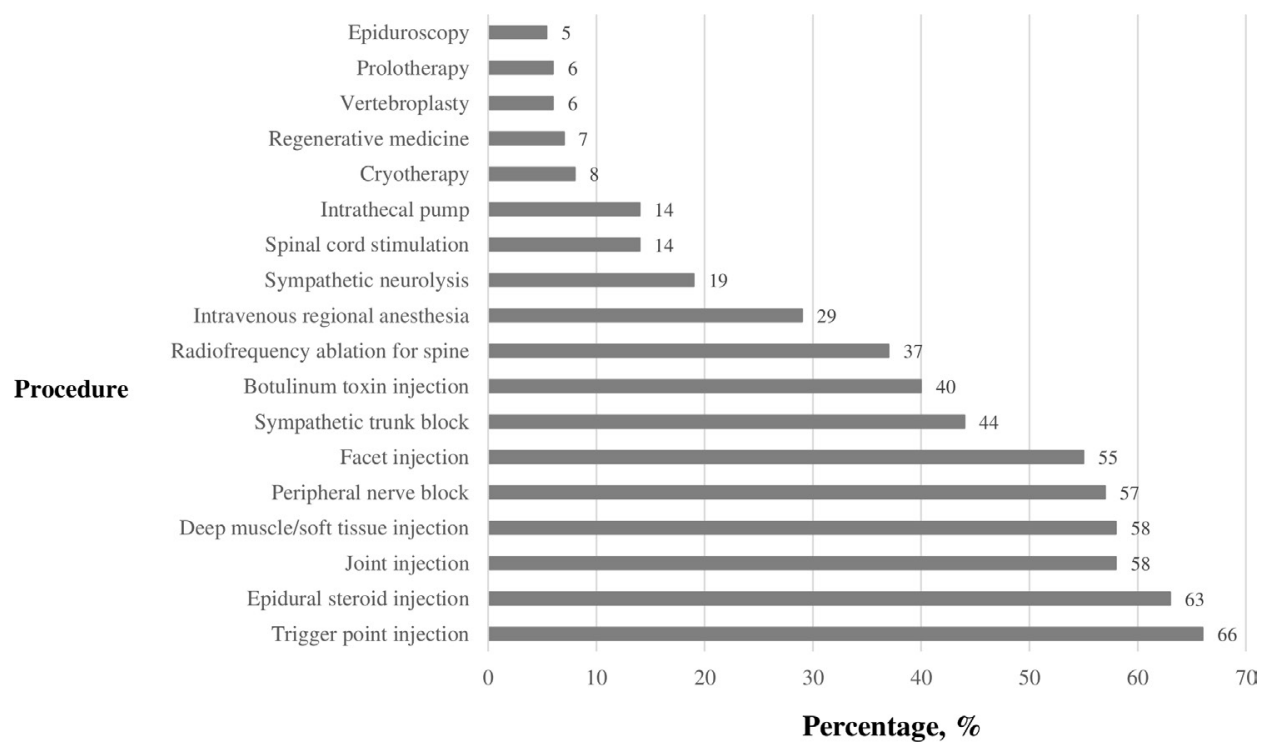

Figure 2 Types of intervention procedure offered in MPTFs in Canada. Data are expressed as percentage of MPTFs. MPTFs, multidisciplinary pain treatment facilities.

(2005-2006: 78\%; 2017-2018: 91\%) and psychological/counseling treatment (2005-2006: 76\%; 2017-2018: 95\%) was noted in the present study. About half of the MPTFs (48.4\%) also offer structured pain management programs, such as low back pain school.

\section{DISCUSSION}

This study reveals that accessing public MPTFs continues to be challenging for Canadians who live with CP, as it was 12 years ago. Most of the facilities are concentrated in large urban cities. Prince Edward Island and the Territories still have no MPTFs. Consequently, patients with CP living in these regions and the majority of Canadians living in rural areas do not have access to such services and are managed by family physicians. The optimal option for CP management is MPTF especially in patients with complex pain issues or concerns about opioid misuse $;{ }^{8-10}$ these facilities offer a variety of biopsychosocial treatment modalities including interventional, physical, and psychological therapies that exceed the resources available to family physicians.
For obvious reasons of equity, the number of community-based MPTFs needs to be increased. In a recent review of the literature commissioned by the Canadian Agency for Drugs and Technologies in Health (CADTH), Gauthier et al's ${ }^{15}$ findings suggest that multidisciplinary management of chronic non-malignant pain is associated with significant improvement in pain intensity and may also contribute to improve quality of life and function.

These findings are consistent with those from another CADTH report published in $2017 .{ }^{16}$ However, there is a paucity of literature on the cost-effectiveness of programs offered in MPTFs. Further research is needed to identify the type of treatment modalities and combinations that would provide optimal benefits for patients with CP. ${ }^{15} 16$ However, whether earlier access to these types of services would translate into cost reductions compared with what is offered now is unknown and merits further investigation.

Another disturbing finding of the present study is that the median wait time for a first appointment in public MPTFs has not really changed in the past decade (5.5 months vs 6 months).

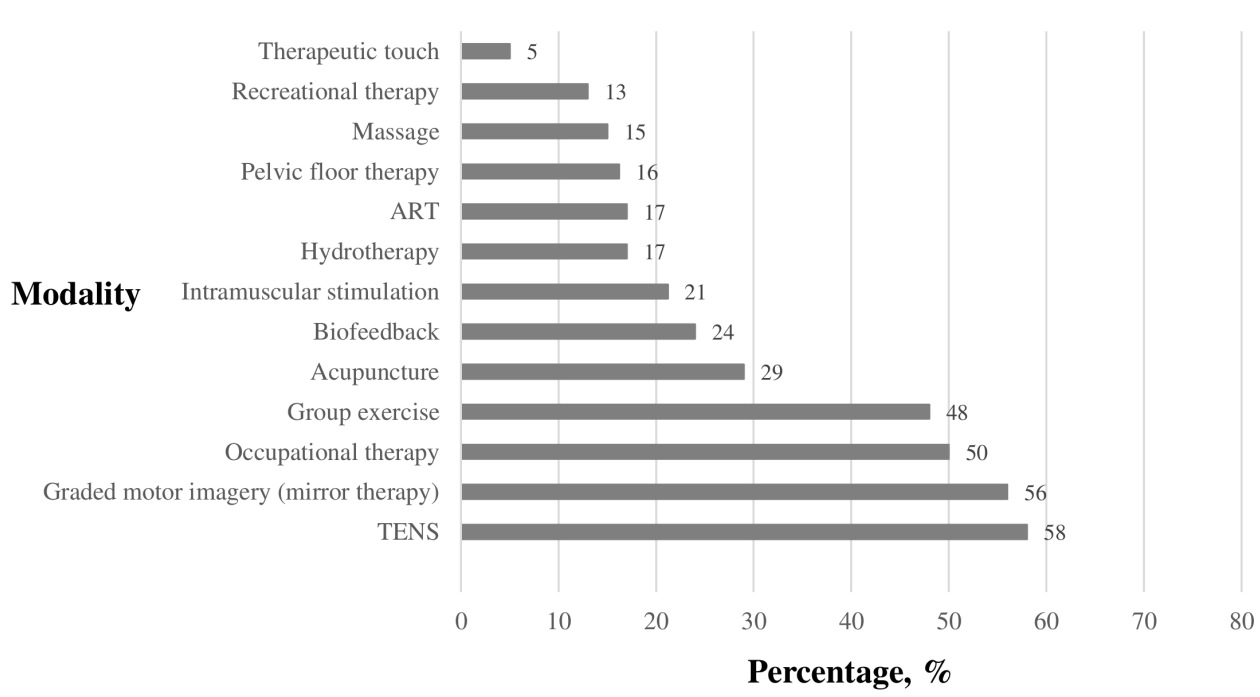

Figure 3 Types of physical modality offered in MPTFs. Data are expressed as percentage of MPTFs. ART, active release technique; MPTFs, multidisciplinary pain treatment facilities; TENS, transcutaneous nerve stimulation. 


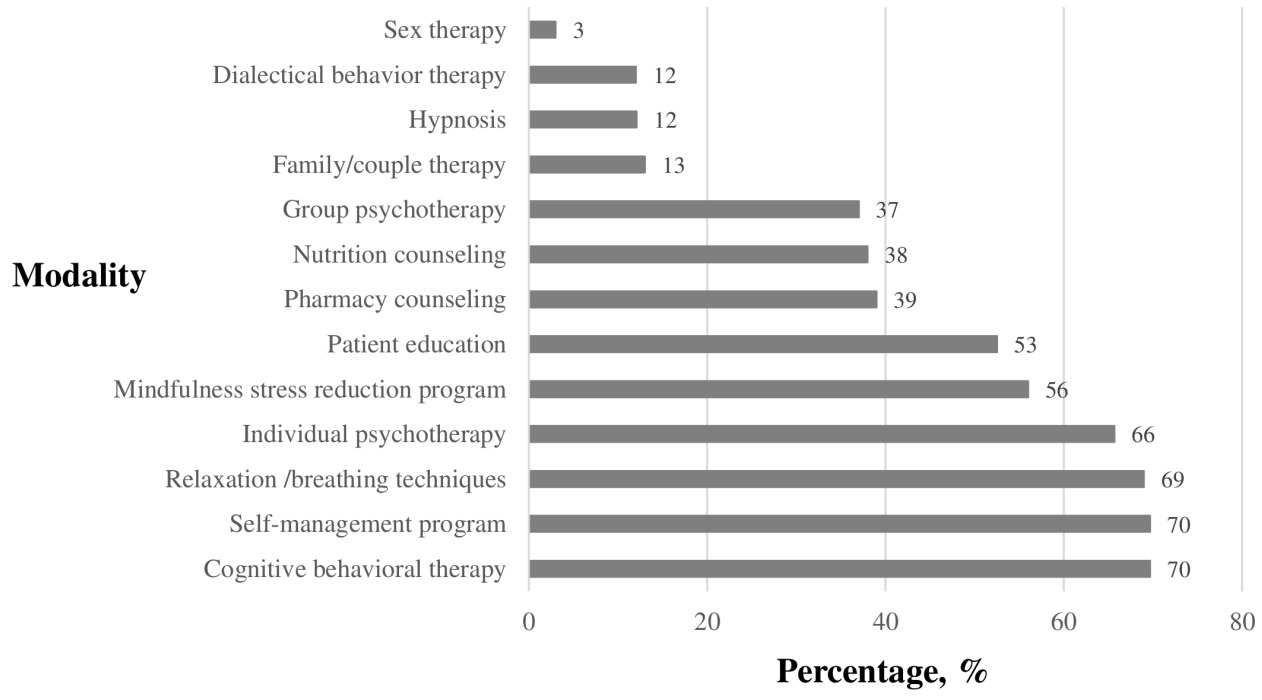

Figure 4 Types of psychological modality offered in MPTFs. Data are expressed as percentage of MPTFs. MPTFs, multidisciplinary pain treatment facilities.

In 2016, Fashler et al ${ }^{17}$ conducted a systematic review of the published literature evaluating MPTFs and provided an overview of their availability, caseloads, wait times, and characteristics. The results show large variability in research methodologies among the sampled 14 studies (eg, search strategy, MPTF definition) and the authors concluded that the availability of pain treatment facilities is scarce in countries such as Australia, Italy, UK, and USA. Consistent with the results reported in the present study, caseloads and wait times were generally high suggesting poor availability of services for people who suffer from CP. Another survey carried out in 2012 in various European countries, Australia, New Zeeland, Israel, and USA ${ }^{18}$ showed similar results in terms of the scarcity pain treatment facilities and especially in the USA except for the Veterans Health Administration system.

Our results suggest that at least $50 \%$ of Canadians with CP have to wait 6 months or more to be seen in public MPTFs, and this wait can be as long as 4 years. In an attempt to identify acceptable wait times for CP treatment in a specialty clinic, Lynch et $a l^{19}$ conducted a systematic review whose results support that wait times of 6 months or more from the time of referral to treatment would be associated with a significant deterioration in patients' health-related quality of life and psychological well-being. However, these authors were unable to identify the specific point at which deterioration becomes most important when taking into account the time elapsed between onset of symptoms (rather than referral) and treatment. To our knowledge, no studies have examined this issue. Further research is also needed to determine the impact of wait times on outcomes/ costs of multidisciplinary pain treatment.

Some positive changes also emerged in the present study. A slight increase in the number of MPTFs has been observed in more than half of the Canadian provinces. The proportion of public to private clinics was found to be substantially higher. The former have been successful in increasing their number of new consultations and the longest wait times for a first appointment have also slightly decreased. Finally, the number of pediatric MPTFs has nearly doubled over the past decade. These results should not be viewed as negligible, especially as there has been in the past 5 years a growing interest and recognition of the importance of CP and its optimal treatment in Canada. In 2016, the Canadian Institutes of Health Research funded the creation of the Chronic Pain Network through its Strategies for Patient Oriented Research (SPOR) Program (\$12.5 million). In 2019, Health Canada put in place the Canadian Pain Task Force which marks a formal commitment by the government to better understand and address the needs of people living with CP.

With regard to the much lower proportion of private MPTFs found in the present study (6.7\% vs $40 \%$ in Peng et al's study), various factors may explain this difference. First, several clinics seem to have ceased their activities. All but one MTPFs in Saskatchewan were privately funded in 2005-2006 and their number dropped from 13 to 3 in 2017-2018. The number of MPTFs in Ontario also decreased from 35 to 25 with surprisingly minimal change in the length of the patient waiting lists. The various possible changes that might explain this finding are unclear but the interesting possibility of increases in efficiency of current MPTFs is worthy of further study. Ontario has put more resources in funding existing MPTFs located in teaching hospitals and this may have resulted in the closure of some community-based MPTFs which prioritized patients with private funding (eg, work-related injury). It is also possible that some private clinics changed their type of clientele (eg, from pain to other musculoskeletal indications). Finally, our response rate was slightly lower than Peng et al's study $(79.4 \%$ vs $85 \%)^{11}$ and it is possible non-respondents were affiliated with private pain clinics.

The fact that accessibility to public MPTFs continues to be limited calls for earlier interventions in primary care settings to minimize patients' suffering and psychological morbidity. Innovative strategies are currently available providing primary care physicians the expertise support and advice from pain specialists working in MPTFs, via online and digital platforms (eg, Atlantic Mentorship Network-Pain and Addiction Network (https:// www.atlanticmentorship.com); Project ECHO (http://www.ruis. umontreal.ca/le-projet-echo-chum-douleur-chronique, https:// uhn.echoontario.ca/chronic-pain-opioid-stewardship); Champlain BASE eConsult (https://www.champlainbaseeconsult.com)). Considering the substantial human and economic costs of $\mathrm{CP}$, there is a need to determine the cost-effectiveness of such initiatives, as well as virtual care services. Whether they may also contribute to decrease the wait list times in tertiary care MPTFs would be another important aspect to measure.

There are a number of limitations to this study. First, we cannot exclude the possibility that we have missed some eligible MPTFs. 
To help mitigate this concern, we had within each province a study champion who had a key role in identifying any missing MPTFs on the list they were provided. Our response rate among the eligible MPTFs was lower than Peng et al (79.4\% vs $85 \%),{ }^{11}$ but it remains satisfactory in the present context. Data such as the number of new consultations or follow-up visits in the past 12 months, as well as average wait times for a first appointment were based on selfreport estimations and should therefore be considered as approximations. Finally, our study excluded modality-oriented clinics (eg, nerve block clinic) and pain clinics operated by a solo practitioner which provide care to patients with CP.

\section{CONCLUSIONS}

This study shows that accessibility to public MPTFs continues to be limited in Canada resulting in lengthy wait times for a first appointment. These results highlight the need to increase the number of community-based MPTFs and virtual care initiatives to distribute pain services into regional and remote areas, in order to provide Canadians who live with CP with optimal care.

\section{Author affiliations}

'Department of Anesthesiology and Pain Medicine, Université de Montréal Faculté de Médecine, Montreal, Quebec, Canada

${ }^{2}$ Research Center, Centre Hospitalier de I'Universite de Montreal, Montreal, Quebec, Canada

${ }^{3}$ Anesthesiology and Pain Medicine, University of Toronto Faculty of Medicine, Toronto, Ontario, Canada

${ }^{4}$ Anesthesiology, University Health Network-Western Hospital, Toronto, Ontario, Canada

${ }^{5}$ Anesthesiology and Perioperative Medicine, Queen's University, Kingston, Ontario, Canada

${ }^{6}$ Anesthesiology, Kingston General Hospital, Kingston, Ontario, Canada

${ }^{7}$ Anestheiology, Michael G DeGroote School of Medicine, McMaster University, Hamilton, Ontario, Canada

${ }^{8}$ Michael F. DeGroote Institute for Pain Research and Care, McMaster University, Hamilton, Ontario, Canada

${ }^{9}$ Epidemiology and Preventive Medicine, Monash University, Melbourne, Victoria, Australia

${ }^{10}$ JPOCSC Pain Management Clinic, Fraser Health Authority, Surrey, British Columbia, Canada

${ }^{11}$ Pediatrics, University of Saskatchewan College of Medicine, Saskatoon,

Saskatchewan, Canada

${ }^{12}$ Pediatrics, Saskatchewan Health Authority, Saskatoon, Saskatchewan, Canada

${ }^{13}$ Pain Clinic, Centre Hospitalier de I'Université de Montréal, Montreal, Quebec, Canada

${ }^{14}$ Department of Anesthesiology and Pain Medicine, University of Toronto Faculty of Medicine, Toronto, Ontario, Canada

${ }^{15}$ Anesthesiology, Women's College Hospital, Toronto, Ontario, Canada

${ }^{16}$ Department of Anesthesia, Pain Management and Perioperative Medicine,

Dalhousie University Faculty of Medicine, Halifax, Nova Scotia, Canada

${ }^{17}$ Center for Pediatric Pain Research, IWK Health Centre, Halifax, Nova Scotia, Canada

${ }^{18}$ Department of Anesthesiology, Perioperative and Pain Medicine, Max Rady College of Medicine, University of Manitoba Faculty of Health Sciences, Winnipeg, Manitoba, Canada

${ }^{19}$ Pain Clinic, Health Sciences Centre, Winnipeg, Manitoba, Canada

${ }^{20}$ Pain Medicine, Department of Anesthesia, The University of British Columbia

Faculty of Medicine, Vancouver, British Columbia, Canada

${ }^{21}$ CHANGEpain Clinic, Vancouver, Quebec, Canada

${ }^{22}$ Family Medicine, University of Calgary Cumming School of Medicine, Calgary, Alberta, Canada

${ }^{23}$ Calgary Chronic Pain Center, Alberta Health Services, Edmonton, Alberta, Canada

Twitter Owen Williamson @DrODWilliamson and Krista Baerg @kbaerg

Acknowledgements The authors gratefully thank all administrative leads of the MPTFs who completed our questionnaire. We also sincerely thank Mrs Kahina Bensaadi who assisted in data collection. Thanks are also due to Mr Alix Cagnin who conducted the statistical analyses and Mrs Geneviève Lavigne who participated in the preparation of the manuscript.

Contributors MC and PP: study design/planning; acquisition, analysis and interpretation of results; manuscript preparation and review. IG, NB, OW, and
AJ-M: acquisition, analysis and interpretation of results; manuscript review. $K B, A B$, TDR, GAF, HI and JP acquisition, analysis, and interpretation of results; manuscript review.

Funding This study was funded by the Chronic Pain Network through the Strategy for Patient-Oriented Research (grant \# SCA-145102), an initiative of the Canadian Institutes of Health Research.

Disclaimer The funding contributor had no role in the design and conduct of the study; the collection, management, analysis or interpretation of the data; the preparation, review or approval of the manuscript; or the decision to submit the manuscript for publication.

Competing interests $\mathrm{KB}$ receives royalties from Brush Education for the book "Teamwork, Leadership, and Communication: Collaboration Basics for Health Professionals."

Patient consent for publication Not required.

Ethics approval This study was approved by the Research Ethics Board of the Centre hospitalier de l'Université de Montréal.

Provenance and peer review Not commissioned; externally peer reviewed.

Data availability statement Data are available on reasonable request.

ORCID iD

Krista Baerg http://orcid.org/0000-0001-5192-7285

\section{REFERENCES}

1 Schopflocher D, Taenzer P, Jovey R. The prevalence of chronic pain in Canada. Pain Res Manag 2011;16:445-50.

2 Reitsma ML, Tranmer JE, Buchanan DM, et al. The prevalence of chronic pain and pain-related interference in the Canadian population from 1994 to 2008. Chronic Dis Inj Can 2011;31:157-64.

3 Institute of Medicine. Relieving pain in America: a blueprint for transforming prevention, care, education, and research. Washington DC: The National Academies Press, 2011. http://www.nap.edu/catalog.php?record_id=13172

4 Breivik H, Collett B, Ventafridda V, et al. Survey of chronic pain in Europe: prevalence, impact on daily life, and treatment. Eur J Pain 2006;10:287-333.

5 Duenas M, Ojeda B, Salazar A, et al. A review of chronic pain impact on patients, their social environment and the health care system. J Pain Res 2016;9:457-67.

6 Choinière $M$, Dion D, Peng $P$, et al. The Canadian STOP-PAIN project - Part 1: who are the patients on the waitlists of multidisciplinary pain treatment facilities? Can J Anesth/J Can Anesth 2010:57:539-48.

7 Gaskin DJ, Richard P. The economic costs of pain in the United States. J Pain 2012:13:715-24

8 Campbell F, Hudspith M, Anderson M, et al. Chronic pain in Canada: laying a foundation for action: a report of the Canadian pain Task force. Ottawa, ON: Health Canada, 2019.

9 Kaiser U, Treede R-D, Sabatowski R. Multimodal pain therapy in chronic noncancer pain — gold standard or need for further clarification? Pain 2017;158:1853-9.

10 Kerns RD, Krebs EE, Atkins D. Making integrated multimodal pain care a reality: a path forward. J Gen Intern Med 2018:33:1-3.

11 Peng $\mathrm{P}$, Choiniere M, Dion D, et al. Challenges in accessing multidisciplinary pain treatment facilities in Canada. Can J Anesth/J Can Anesth 2007;54:977-84.

12 Statistics Canada. (2008). Report on the demographic situation in Canada 2005 and 2006. catalogue No. 91-209-X ISSN 1718-7788. Available: https://www150.statcan. gc.ca/n1/pub/91-209-x/91-209-x2004000- eng.pdf [Accessed 11 Jul 2020].

13 Statistics Canada. (2019). Annual demographic estimates: Canada, provinces and territories 2019. catalogue No. 91-215-X ISSN 1911-2408. Available: https:// www150.statcan.gc.ca/n1/pub/91-215-x/91-215- x2019001-eng.pdf [Accessed 11 Jul 2020].

14 Lynch ME, Williamson OD, Banfield JC. COVID-19 impact and response by Canadian pain clinics: a national survey of adult pain clinics. Canadian Journal of Pain 2020;4:204-9.

15 Gauthier K, Dulong C, Argaez C. Multidisciplinary Treatment Programs for Patients with Chronic Non-Malignant Pain: A Review of Clinical Effectiveness, CostEffectiveness, and Guidelines - An Update. Ottawa (ON: CADTH Rapid Response Reports, 2019.

16 Banerjee S, Argaez C. Multidisciplinary treatment programs for patients with chronic non- malignant pain: a review of clinical effectiveness, cost-effectiveness, and guidelines. Ottawa (ON: CADTH rapid response reports, 2017.

17 Fashler SR, Cooper LK, Oosenbrug ED, et al. Systematic review of multidisciplinary chronic pain treatment facilities. Pain Res Manag 2016;2016:1-19.

18 Schatman ME. Interdisciplinary chronic pain management: international perspectives. Pain Clinical Updates 2012;20:1-5.

19 Lynch ME, Campbell F, Clark AJ, et al. A systematic review of the effect of waiting for treatment for chronic pain. Pain 2008;136:97-116. 